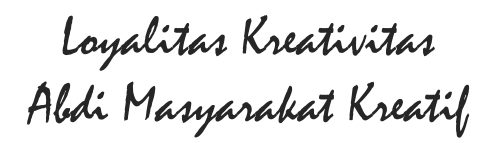

Loyalitas Kreativitas

Aldi Masyarakat Kreatif

Program Studi Ekonomi Manajemen Universitas Pamulang

Jurnal LOKABMAS Kreatif Vol. 01, No. 01, Hal. 1-7

Email:jurnalkreatif.manajemen@gmail.com

\title{
PEMANFAATAN KAIN PERCA SEBAGAI AKSESORIS MOTIF HIASAN PADA PAKAIAN DAN TAS SEBAGAI BENTUK PELUANG USAHA
}

\author{
Vega Anismadiyah, Ivan Putranto, Ana Septia Rahman., \\ Iis Noviyanti, Iriana Kusuma Dewi \\ Dosen Ekonomi Fakultas Ekonomi Universitas Pamulang \\ Email dosen02218@unpam.ac.id, dosen01675@unpam.ac.id,
}

\begin{abstract}
ABSTRAK
Tujuan dari Kegiatan Pengabdian Kepada Masyarakat adalah untuk melaksanakan salah satu Tri Dharma Perguruan Tinggi. Selain itu diharapkan dengan pengabdian kepada masyarakat tersebut keberadaan perguruan tinggi dapat memberikan kontribusi besar kepada pengembangan dan penerapan keilmuan kepada masyarakat.

Metode pelaksanaan pengabdian ini dilakukan dalam beberapa kegiatan yaitu tahap survei yaitu sosialisasi dilakukan dengan menyusun berbagai hal yang akan disampaikan pada saat kegiatan pengabdian yang akan dilakukan yang meliputi: penyusunan materi yang akan diberikan, penyusunan jadwal pemberian materi, pembagian tugas tim pengabdian dan survei ke lokasi pengabdian. Tahap sosialisasi yaitu sebelum kegiatan pengabdian dilaksanakan terlebih dahulu dilakukan tahap sosialisasi yaitu melakukan silaturahmi dengan kepala sekolah, menyampaikan maksud dan tujuan pengabdian ini. Pada tahap ini juga dilakukan jalinan kerjasama dan menentukan jadwal kegiatan pengabdian. Tim pelaksana kegiatan pengabdian pada masyarakat adalah dosen Fakultas Ekonomi jurusan manajemen sebanyak 5 orang. Tim pengabdian memberikan materi tentang Pelatihan Pemanfaatan Kain Perca Sebagai Aksesoris Motif Hiasan Pada Pakaian Dan Tas Sebagai Bentuk Peluang Usaha, di PKBM Negeri 26 Bintaro.

Hasil pengabdian masyarakat yang diperoleh adalah bertambahnya keilmuan bagi Para Peserta (Siswa/siswi) PKBM Negeri 26 Bintaro agar mereka memiliki keterampilan tambahan dalam memanfaatkan limbah kain perca sehingga mereka memiliki bekal tambahan untuk menghasilkan pendapatan sendiri. Ilmu yang diperoleh pada Pengabdian Masyarakat kali ini diharapkan mampu memberikan semangat baru bagi kita dalam menyampaikan materi dan motivasi serta berkontribusi bagi generasi muda, baik dilingkungan sekolah, kampus dan keluarga.
\end{abstract}

\section{Kata Kunci: Hiasan, Perca, Usaha}

\section{ABSTRAC}

The purpose of community service is to implement one of Tri Dharma colleges. In addition, it is expected that with devotion to the community the existence of universities can contribute greatly to the development and application of scholarly to the community.

This method of devotion implementation is done in several activities namely the survey stage that is socialization is done by arranging various things to be delivered during the dedication activities that will be conducted which include: the preparation of materials that will be given, drafting the awarding schedule, the division of tasks of devotion teams and surveys to the location of devotion. Socialization stage is before the dedication activities carried out first conducted socialization stage is doing a relationship with the principal, convey the intent and purpose of this devotion. At this stage is also done cooperation and determine the schedule of the dedication activities. The team of community dedication activities is the Faculty of Economics lecturer in management as many as 5 people. The 


\section{Loyalitas Kreativitas \\ Aldi Masyarakat Kreatif}

P-ISSN 2722-2101, E-ISSN 2722-4201

Program Studi Ekonomi Manajemen Universitas Pamulang Jurnal LOKABMAS Kreatif Vol. 01, No. 01, Hal. 1-7

Email:jurnalkreatif.manajemen@gmail.com

dedication team provides material about patchwork training as accessories Motif decoration on clothes and bags as a form of business opportunity, in PKBM Negeri 26 Bintaro.

The results of the public devotion is increasing scholarship for the participants (students) PKBM Negeri 26 Bintaro so that they have additional skills to utilize patchwork waste so that they have additional provisions to generate their own income. Science gained on community service this time is expected to provide a new spirit for us in delivering the material and motivation and contributing to the young generation, both in school, campus and family.

\section{Keywords: ornament, Perca, business}

\section{PENDAHULUAN}

Di era globalisasi ini, memperoleh pekerjaan bukanlah hal yang mudah karena semakin ketatnya persaingan di dunia kerja. Para pencari kerja bukan hanya bersaingan dengan sesama pencari kerja dalam negeri, tetapi juga bersaingan dengan tenaga kerja dari mancanegara.

Pada bulan Februari 2018, BPS melaporkan bahwa jumlah pengangguran di Indonesia sebanyak 6,87 juta jiwa. Sebaran Jumlah Pengangguran di Indonesia Kepala BPS, Suhariyanto, menyebutkan bahwa Tingkat Pengangguran Terbuka terbanyak berada di Jawa Barat, yang berada di angka $8,16 \%$. Di posisi kedua dan ketiga ada Banten di angka 7,72\% dan Maluku di angka 7,38\%. Persentase pengangguran paling rendah berada di Bali dengan 0,86\%, Sulawesi Barat dengan $2,45 \%$, dan Bengkulu dengan $2,70 \%$. Sedangkan jika dilihat dari tingkat pendidikan, lulusan Sekolah Menengah Kejuruan atau SMK menyumbang porsi pengangguran terbanyak, yaitu sebesar $8,92 \%$.

Masih tingginya tingkat pengangguran di Indonesia, memicu lahirnya UMKM (Usaha Mikro Kecil Menengah) sebagai salah satu solusi mengurangi pengangguran. UMKM merupakan salah satu roda penggerak perekonomian Indonesia. Menurut Kementerian Koperasi dan UKM, sumbangan UMKM terhadap PDB Indonesia mencapai angka 60,34 persen pada tahun 2017. Artinya sekitar 60 persen nilai barang dan jasa yang diproduksi di Indonesia pada tahun 2017 berasal dari sektor UMKM.

Salah satu jenis UMKM yang menjanjikan di masa depan adalah bisnis fashion. Usaha dibidang fashion sepertinya masih menjadi primadona di Indonesia, terutama yang dilakukan secara online.
Menurut The Jakarta Post, produk fashion menjadi salah satu incaran favorit orang Indonesia ketika berbelanja online. Lingkup industri fashion sendiri sangat luas, dari baju, celana, rok, jilbab, tas, sepatu hingga aksesoris.

Bisnis di bidang fashion ini, selain menguntungkan juga memiliki peluang yang sangat luas. Karena itu, kompetisi di bisnis ini juga cukup ketat. Hal yang harus dilakukan oleh pebisnis fashion adalah selalu mengikuti tren yang sedang diminati pasar. Pebisnis fashion harus pandai membaca keinginan dan kebutuhan pasar.

Pada dasarnya, banyak sekali bahan yang bisa digunakan sebagai bahan baku bisnis fashion ini. Pada kesempatan ini, bahan yang akan digunakan dalam bisnis fashion ini adalah kain perca. Kain perca digunakan karena bisa menghasilkan produk yang unik, mudah dibuat, mudah didapat, dan dengan memanfaatkan kain perca menjadi produk baru, berarti kita ikut menjaga kelestarian lingkungan karena mengurangi sampah kain yang sulit diurai oleh mikrobakteri. Bisnis ini membutuhkan modal yang tidak terlalu besar, karena itu cocok untuk orang yang baru mulai mencoba berkecimpung di dunia bisnis.

\section{RUMUSAN MASALAH}

Dengan mempertimbangkan latar belakang yang telah dijelaskan diatas kami berinisiatif untuk membentuk pengabdian masyarakat bagi siswa dan siswi yang bersekolah di PKBM Negeri 26 Bintaro khususnya dalam program pelatihan agar para siswa memiliki keterampilan dalam membuat hiasan pakaian dan tas dari limbah kain perca yang memilikki nlai jual sebagai peluang bisnis yang menarik. TUJUAN PELAKSANAAN 


\section{Loyalitas Kreativitas \\ Aldi Masyarakat Kreatif}

P-ISSN 2722-2101, E-ISSN 2722-4201

Program Studi Ekonomi Manajemen Universitas Pamulang

Jurnal LOKABMAS Kreatif Vol. 01, No. 01, Hal. 1-7

Email:jurnalkreatif.manajemen@gmail.com
1. Memberikan pengetahuan kepada siswa dan siswi PKBM Negeri 26 Bintaro mengenai peluang usaha yang bisa dimanfaatkan untuk menambah penghasilan.

2. Memberikan pengetahuan kepada siswa dan siswi PKBM Negeri 26 Bintaro mengenai cara membuat hiasan pakaian dari limbah kain perca.

\section{TINJAUAN PUSTAKA}

Menurut Sicilia Sawitri, dkk (2010:406) industri garmen merupakan industri yang mengolah sebuah produk yang berasal dari penggabungan dan penjahitan berbagai potongan dan komponen hingga menjadi suatu bentuk jadi berupa busana. Sedangkan kain perca merupakan limbah garmen yang berupa sisa potongan pada proses pengguntingan kain, baik pada pembuatan pakaian yang dilakukan oleh ibu rumah tangga, industri kecil, maupun industri besar.

Dalam dunia kerajinan, dikenal suatu jenis kain bernama kain perca. Berbeda dari kain flanel atau jenis kain lainnya yang tersedia di pasaran, kain perca merupakan sisa potongan dari gulungan kain yang tidak dipakai lagi dalam proses produksi pakaian, tas, maupun produk tekstil lainnya. Kain perca biasanya berbahan katun, rayon, kaos, Teteron Cotton (TC), wool, lycra, ceruti, chiffon, satin, denim, sutra, polyester dan flanel dengan warna dan motif beragam. Di dalam dunia perkainan, kain perca acap kali disebut dengan majun. Walau demikian, ternyata pemanfaatan kain perca sama banyaknya dengan jenis kain yang lain.

Potongan kain yang dianggap sudah tidak punya nilai jual lagi karena merupakan sisa pembuatan ini sebenarnya memiliki banyak sekali potensi dijadikan kerajinan tangan dengan nilai jual tinggi. Dengan keterampilan dan sedikit modal, bisa menjadi produsen kerajinan dengan keuntungan lumayan. Tak hanya nilai jualnya tinggi, kreasi dari kain perca sangat unik.

Kerajinan tangan dari kain perca merupakan salah satu kerajinan paling tua di dunia. Teknik untuk menggabungkan potongan-potongan kain menjadi satu barang sudah mulai dilakukan sejak ribuan tahun lalu. Bahkan, bangsa Mesir dan Cina Kuno dikenal pernah melapisi baju perang mereka dengan kain perca.

Sejarah membuktikan bahwa kerajinan dari kain perca sudah ada sejak sekitar 5 ribu tahun yang lalu. Semakin lama, makin banyak teknik kerajinan kain perca yang berkembang. Di abad 11 sampai 12, orang-orang semakin banyak menggunakan kain perca untuk mengkreasikan berbagai kebutuhan sehari-hari seperti selimut, baju, dan lain-lain.

Kreasi dan gaya baru kreasi kain perca pun semakin banyak bermunculan. Semakin lama, kreasi kain perca tak hanya memperhatikan fungsinya, namun juga keindahannya. Kerajinan kain perca pun juga menyebar ke seluruh dunia lewat pengembaraan.

Semakin lama, kerajinan kain perca tak hanya memanfaatkan kain yang merupakan "sisa", namun juga ada yang menggunakan kain baru yang sengaja dipotong-potong. Kemudian kain baru yang sudah dipotong sesuai keinginan ini dijahit dan dibentuk sedemikian rupa sehingga menghasilkan suatu kerajinan baru yang berkualitas tinggi, nyaman, serta sesuai selera pemakai. Saat ini, motif perca juga sering digunakan oleh para desainer untuk membuat busana.

Sejak berkembangnya kerajinan kain perca atau quilting pada abad ke-19 di Amerika, Eropa, China, dan Mesir, sekarang kerajinan kain perca sudah semakin menyebar ke seluruh dunia termasuk Indonesia. Beberapa tahun belakangan, kain perca dipandang sebagai suatu kesenian terapan yang indah. Karena paduan warna yang indah dan nyamannya, tak heran jika busana dan aksesoris berhiaskan kain perca semakin menjamur di butik-butik ternama.

Jika tertarik dengan dunia kreasi kerajinan kain perca, bisa belajar membuat dan menghasilkan karya yang tidak kalah berkualitas. Mulailah belajar dari teknik-teknik dasar terlebih dahulu dan kemudian mulai mengembangkan kreasi setelah anda cukup mahir. Untuk mempelajari kerajinan perca ini, bisa belajar secara otodidak dengan membaca berbagai buku panduan yang bisa ditemukan di berbagaitokobuku, baik online maupun offline. 


\section{Loyalitas Kreativitas \\ Aldi Masyarakat Kreatif}

P-ISSN 2722-2101, E-ISSN 2722-4201

Program Studi Ekonomi Manajemen Universitas Pamulang Jurnal LOKABMAS Kreatif Vol. 01, No. 01, Hal. 1-7

Email:jurnalkreatif.manajemen@gmail.com
Selain itu, juga bisa belajar langsung dari para pengrajin kain perca yang saat ini sudah cukup banyak yang membuka kursus kerajinan perca untuk umum. Bentuk Guntingan Kerajinan Kain Perca

Ada beberapa bentuk guntingan yang biasa dibuat dalam mempersiapkan potonganpotongan kain dalam kerajinan ini. Hal ini dilakuakn sebelum digabungkan dan dijahit kembali secara detil dan rapih.

a. Bentuk Segitiga

Potongan kain dipotong menjadi bentuk segitiga dengan beragam ukuran, potongan kain segitiga banyak dipakai untuk membentuk motif sisik, rumput, dll. Bentuk ini adalah bentuk yang paling sederhana.

b. Bentuk Persegi

Bentuk persegi ataupun bentuk persegi panjang, cocok bagi para pemula. Mengapa? Karena bentuk ini juga sama mudahnya dengan segitiga untuk dipotong, bentuk persegi ini bisa dipakai dalam berbagai motif seperti papan catur, dll.

c. Bentuk Geometri lainnya

Selain bentuk persegi dan segitiga, masih banyak lagi bentuk geometri lainnya seperti segi lima, segi enam, dll. Semakin banyak sisinya maka semakin sulit untuk dipotong, contoh bentuk yang diaplikasikan untuk motif adalah segi delapan untuk motif sarang lebah, dll.

d. Bentuk Manusia, Hewan dan Tumbuhan

Biasanya bentuk ini dipakai sebagai pemanis, tapi banyak juga yang memakai bentuk ini untuk motif utama. Bentuknya yang lucu dan bervariatif membuat banyak orang menyukai bentuk yang satu ini.

Teknik-Teknik Menjahit Kain Perca

Dalam proses untuk menghasilkan karya dari kerajinan tangan berbahan dasar kain perca, diperlukan beberapa teknik menjahit diantaranya :

a. Teknik Patchwok, proses yang dilakukan dalam teknik ini secara prinsip adalah dengan menjahit kain perca sesuai potongannya, sehingga untuk menggunakan teknik ini hanya perlu belajar menjahit secara lurus. Secara umum teknik ini dilakukan dengan menyambung setiap potongan kain perca dengan jahitan sehingga nantinya dapat membentuk motif motif tertentu dalam lembar kain gabungan beberapa kain kain perca yang nantinya diproses lagi untuk menghasilkan kerajinan tangan.

b. Teknik Applique, teknik ini memiliki perbedaan dengan teknik patchwok, secara prinsip teknik ini adalah proses membuat motif dari kain perca yang ditempelkan kepada kain yang masih utuh. Kain perca dalam teknik ini hanya bertindak sebagai hiasan pada sebuah background kain yang utuh. Teknik ini dapat digunakan untuk menghias beberapa barang berbahan dasar kain.

c. Teknik Quilting, teknik ini memiliki prinsip untuk menambahkan masa berupa busa atau sejenisnya pada kain perca yang sudah dijahit. Hasil karya dari kerajinan tangan menggunkan kain perca dengan teknik quilting ini akan menghasilkan sebuah benda yang memiliki masa tebal serta berbentuk tiga dimensi. Karena bentuknya, kerajinan dari kain perca dengan teknik ini dapat termasuk kedalam karya seni rupa tiga dimensi. Selain busa, bahan lain yang juga sering dan familiar dapat digunakan untuk mengisi ruang di dalam kain perca adalah dakron.

d.

\section{HASIL DAN PEMBAHASAN}

Kegiatan Pengabdian Masyarakat Universitas Pamulang yang dilakukan oleh dosen-dosen program studi Manajemen telah berjalan dengan lancar dan mendapat sambutan hangat dari tempat pelaksanaan kegiatan ini yaitu di PKBM Negeri 26 di Bintaro Jakarta Selatan .

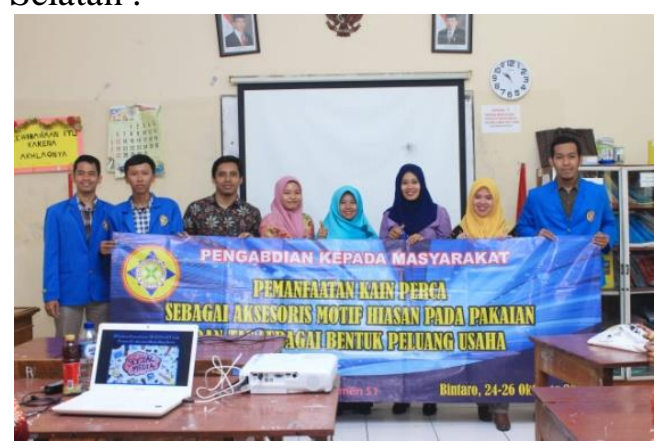

Harapan kami dengan pengabdian ini adalah meningkatnya pengetahuan dan 


\section{Loyalitas Kreativitas \\ Aldi Masyarakat Kreatif}

P-ISSN 2722-2101, E-ISSN 2722-4201

Program Studi Ekonomi Manajemen Universitas Pamulang Jurnal LOKABMAS Kreatif Vol. 01, No. 01, Hal. 1-7

Email:jurnalkreatif.manajemen@gmail.com keterampilan siswa dalam membuat hiasan pakaian dan tas dengan memanfaatkan limbah kain perca dan meningkatnya jiwa enterpreuneur para siswa sehinga mereka tertarik untuk memanfaatkan kain perca sebagai peluang usaha.

\section{KESIMPULAN DAN SARAN Kesimpulan}

Pengetahuan dan pemahaman siswa dan siswi PKBM Negeri 26 Bintaro tentang memanfaatkan limbah kain perca menjadi hiasan pakaian dan tas sebagai peluang usaha menjadi bertambah. Dan semakin meningkatnya jiwa enterpreuneur siswa dan siswi sehingga menimbulkan minat untuk berwirausaha.

\section{Saran}

Mengadakan sosialisasi dan pelatihan serupa pada siswa sekolah lain di Kecamatan yang lain, dengan materi yang serupa. Adanya kesinambungan program pasca kegiatan pengabdian ini sehingga para siswa benar-benar dapat mengembangkan kemampuannya dalam berkreasi. Diadakannya kegiatan yang berkaitan dengan pemasaran produk yang sudah dihasilkan.

\section{DAFTAR PUSTAKA}

Muljono, Ryan Kristo. 2018. Digital Marketing Concept. Gramedia Pustaka Utama. Jakarta.

Pasaribu, V. L. D., Agrasadya, A., Shabrina, N., \& Krisnaldy, K. (2020). MENJADI ENTERPRENEUR MUDA YANG MEMILIKI JIWA LEADERSHIP UNTUK MENGHADAPI MASA DEPAN. Abdi Laksana, 1(1)

Pasaribu, V. L. D., Elburdah, R. P., Sudarso, E., \& Fauziah, G. (2020). PENGGUNAAN MANAJEMEN WAKTU TERHADAP PENINGKATAN PRESTASI BELAJAR DI SMP ARAISIYAH. Jurnal ABDIMAS, 1(1)

Pasaribu, V. L. D., Susanti, F., \& Hartuti, E. T. K. (2019). MEMOTIVASI SISWA DAN SISWI SMK LETRIS INDONESIA DI

\section{DALAM MENENTUKAN PILIHAN UNTUK MELANJUTKAN PENDIDIKAN ATAU BEKERJA SETELAH LULUS SEKOLAH. Jurnal Pengabdian Dharma Laksana, 1(2), 161-172.}

Paluzi, Hanna. 2016. Kreasi Perca (Buku Kreasi Anak). Indiva Media Kreasi. Surakarta.

Tripratiwi, Agni. 2015. Desain Flanel dan Perca. Tiara Aksa. Surabaya.

https://www.jurnal.id/id/blog/4-jenis-strategipemasaran-produk-yang-perlu-anda-ketahui/

https://databermanfaat.blogspot.com/2014/06/ berbagi-makalah-bertemakan-kain-perca.html

https://bisnisukm.com/memanfaatkan-kainperca-sebagai-peluang-usaha.html

https://olympics30.com/kerajinan-darikain-perca/

https://ilmuseni.com/seni-rupa/kerajinantangan/macam-macam-kerajinan-tangan-darikain-perca

https://www.berbagaireviews.com/2018/08/ker ajinan-kain-perca-bahan-kain-perca.html?m=1

https://santaidamai.com/kerajinan-dari-kainperca/

http://repositori.kemdikbud.go.id/1230/1/Baha n\%20belajar\%20perca\%20lengkap-w.pdf

https://club.iyaa.com/bbs/board.php?bo_table= DIY\&wr_id=157

\section{DOKUMENTASI KEGIATAN}




$\begin{array}{cl}\text { Loyalitas Kreativitas } & \text { P-ISSN 2722-2101, E-ISSN 2722-4201 } \\ \text { Aledi Masyarakat Kreatif } & \text { Program Studi Ekonomi Manajemen Universitas Pamulang } \\ & \text { Jurnal LOKABMAS Kreatif Vol. 01, No. 01, Hal. 1-7 } \\ & \text { Email:jurnalkreatif.manajemen@ gmail.com }\end{array}$
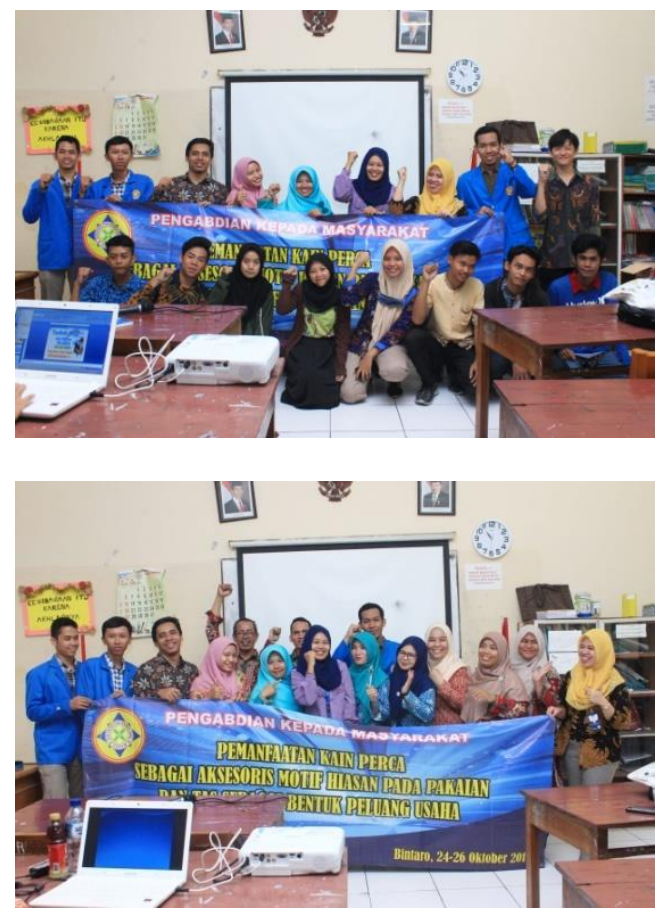